\title{
ACADEMIC SUPERVISION: EFFORTS TO IMPROVE THE LEARNING PROCESS SKILLS OF ELEMENTARY SCHOOL TEACHERS
}

\author{
Farida $^{1}$, Ary Kiswanto Kenedi ${ }^{2}$ \\ ${ }^{1}$ SDN 28 Rawang Timur, Padang, Indonesia \\ ${ }^{2}$ Universitas Samudra, Langsa, Indonesia \\ Ifarida1971.ida@gmail.com, 2arykenedi@unsam.ac.id
}

\begin{abstract}
This research was motivated by findings regarding the learning process of elementary school teachers that were not in accordance with the characteristics of learning at schools. The findings revealed that teachers still used lesson plans which were only downloaded from the internet, the learning process and assessment carried out by teachers were still not in accordance with the demands of the curriculum. Therefore, an effort was needed to improve it. The purpose of this study was to determine the improvement of teacher skills in carrying out the learning process using a problem centered learning model through academic supervision activities. This research was a school action research by adapting the process of implementing from Mc Taggart and Kemmist's classroom action research. This research consisted of stages of planning, implementation, observation and reflection. This research activity was carried out at SDN 28 Rawang Timur, Padang involving 10 teachers. Based on the research conducted, it was found that the teacher got an average skill score of 88.86 in cycle 1 and got an average score of 83.59 in cycle 2 . This concluded that there was an increase in teachers' learning process skills through academic activities. This study suggested that it was necessary to agree on a schedule with the teacher so that the implementation of supervision could be carried out optimally. The implications of this research that it could be used as a basis by supervisors to improve the learning process skills of elementary school teachers.
\end{abstract}

Keywords: academic supervision, learning process, teacher, elementary school

\section{SUPERVISI AKADEMIK : UPAYA PENINGKATAN KETERAMPILAN PROSES PEMBELAJARAN GURU SEKOLAH DASAR}

\begin{abstract}
ABSTRAK
Penelitian ini dilatarbelakangi oleh banyak temuan mengenai proses pembelajaran guru sekolah dasar yang tidak sesuai dengan karakteristik pembelajaran di sekolah. Berdasarkan temuan guru masih menggunakan RPP yang hanya di unduh dari internet, proses pembelajaran dan penilaian yang dilaksanakan oleh guru masih belum sesuai dengan tuntuttan kurikulum. Oleh sebab itu diperlukan sebuah upaya untuk memperbaikinnya. Tujuan penelitian ini adalah untuk mengetahui peningkatkan keterampilan guru dalam melaksanakan proses pembelajaran menggunakan model problem centered learning melalui kegiatan supervisi akademik. Penelitian ini merupakan penelitian tindakan sekolah dengan menyadur proses pelaksanaan penelitian tindakan kelas Mc Taggart dan Kemmist. Penelitian ini terdiri dari tahap perencanaan, pelaksanaan, pengamatan dan refleksi. Kegiatan penelitian ini dilaksanakan di SDN 28 Rawang Timur Kota Padang sebanyak 10 guru. Berdasarkan penelitian yang dilakukan ditemukan guru mendapatkan skor rata-rata keterampilan pada siklus 1 sebesar 88.86 dan mendapatkan skor rata-rata pada siklus 2 sebesar 83.59 . Hal ini menyimpulkan bahwa terjadinya peningkatan keterampilan proses pembelajaran guru melalui kegiatan akademik. Penelitian ini menyarankan agar perlu kesepakatan jadwal dengan guru agar pelaksanaan supervisi dapat terlaksana dengan optimal. Implikasi penelitian ini dapat dijadikan sebagai landasan oleh supervisor untuk dapat meningkatkan keterampilan proses pembelajaran guru sekolah dasar.
\end{abstract}

Kata Kunci: supervisi akademik, proses pembelajaran, guru, sekolah dasar

\begin{tabular}{|c|c|c|}
\hline Submitted & Accepted & Published \\
\hline 14 Juni 2021 & 08 September 2021 & 17 September 2021 \\
\hline
\end{tabular}

\begin{tabular}{|l|l|l|l|}
\hline Citation & $:$ & $\begin{array}{c}\text { Farida., \& Kenedi, A.K. (2021). Academic Supervision: Efforts to Improve the Learning Process Skills of Elementary } \\
\text { School Teachers. Jurnal PAJAR (Pendidikan dan Pengajaran), 5(5), 1483-1489. DOI : } \\
\text { http://dx.doi.org/10.33578/pjr.v5i5.8517. }\end{array}$ \\
\hline
\end{tabular}

\section{PENDAHULUAN}

Proses penyelenggaraan sistem pendidikan di sekolah akan berpengaruh kepada mutu dan kualitas pendidikan di sekolah tersebut (Kenedi et al, 2019). Kualitas dan mutu

pendidikan suatu sekolah akan tergambar dari proses pelakasanaan yang dilakukan (Kenedi et al, 2018). Termasuk di dalamnya proses bagaimana sekolah menghasilkan siswa yang berprestasi serta 
menghasilkan lulusan yang dapat bersaing secara global. Hal ini dapat tercapai apabila proses pembelajaran yang dilaksanakan oleh guru dapat mencapai tujuan pembelajaran yang telah ditetapkan.

Proses pembelajaran yang dilaksanakan akan berdampak kepada mutu pembelajaran (Eliyasni et al, 2019). Mutu pembelajaran merupakan bentuk dari eksistensi guru. Guru tidak hanya saja bertindak sebagai sosok yang menyampaikan pembelajaran saja namu guru memiliki fungsi yang lebih luas dari pada hal tersebut (Eliyasni et al, 2019). Guru harus mampu meningkatkan kinerja agar dapat mengembangkan proses pembelajaran yang dapat mencapai tujuan pembelajaran yang telah ditetapkan.

Kinerja seorang guru adalah gambaran kemampuan guru dalam merancangan, melaksanakan dan melakukan penilaian pembelajaran (Hendri and Kenedi, 2019). Kinerja guru ini akan berkiatan dengan kualitas, kuantitas dan keandalan guru dalam melaksanakan proses pembelajaran (Kuncoro and Dardari, 2017). Guru yang memiliki kinerja yang tinggi akan mampu meningkatkan kualitas Pendidikan dalam proses pembelajaran.

Kinerja guru akan menentukan kualitas diri seorang guru (Kenedi et al, 2018). Kualitas guru merupakan komponen penting yang dapat mempengaruhi kualitas pendidikan yang mana kualitas pendidikan diperlihatkan oleh prestasi belajar siswa (Kenedi et al, 2019). Rendahnya kualitas guru juga akan berpengaruh terhadap rendahnya kualitas pendidikan suatu negara. Oleh sebab itu perlu dipastikan bahwa kualitas guru disuatu negara harus tinggi agar dapat menghasilkan lulusan yang memiliki kompetensi yang tinggi juga.

Mutu seorang guru merupakan salah satu bagian dari proses pembelajaran (Kenedi et al, 2019). Kemampuan guru dalam mengelola pelaksanaan pembelajaran diharapkan dapat menghasilkan lulusan yang berkualitas baik dari segi keterampilan, pengetahuan dan sikap serta mampu bersaing secara global (Astimar et al, 2019). Oleh sebab itu perlu dipastikan agar setiap guru memiliki mutu yang tinggi. Mutu, kualitas dan kinerja guru dapat dinilai dari sebuah kegiatan yang disebut supervisi akademik (Pambudi and Gunawan, 2020). Supervisi akademik merupakan kegiatan yang dilakukan oleh pimpinan untuk meningkatkan kualitas dan kinerja seorang guru (Rahabav, 2016). Kegiatan supervisi ini dapat dilakukan oleh kepala sekolah kepada guru.

Tujuan utama supervisi akademik adalah melakukan pembinaan kepada guru dalam meningkatkan mutu pelaksanaan proses pembelajaran di sekolah (Rasmita, 2019). Objek utama kegiatan supervisi akademik adalah proses pembajaran yang meliputi perencanaan pembelajaran, pelaksanaan pembelajaran dan penilaiaan hasil belajar (Adewale, 2014). Kepala sekolah yang merupakan seorang supervisor memiliki tanggung jawab untuk dapat mengawasi dan memperbaiki pelaksanan proses pembelajaran guru dengan tujuan untuk memperbaiki kualitas dan mutu pembelajaran di sekolah tersebut (Budiarti et al, 2020). Peneliti yang juga seorang kepala sekolah memiliki tanggung jawab untuk memantau proses pembelajaran yang dilaksanakan oleh guru. Oleh sebab itu peneliti melakukan observasi terhadap proses pembelajaran yang dilaksanakan oleh guru.

Observasi tersebut dilaksanakan di SDN 28 Rawang Timur Kota Padang. Berdasarkan hasil observasi tersebut ada beberapa informasi yang didapatkan yaitu guru tidak mengembangkan RPP sendiri melainkan mengunduh dari internet. Proses pembelajaran yang dilaksanakan oleh guru masih bersifat konvensional sehingga berdampak kepada hasil belajar siswa yang masih rendah. Guru masih belum menggunakan model yang inovatif sehingga proses pembelajaran masih bersifat teacher center. Selain itu Ketika peneliti melihat format penilaian guru, guru masih berfokus kepada penilaian pengetahuan saja. Berdasarkan analisis peneliti terhadap temuan ini adalah proses pelaksanaan pembelajaran yang dilaksanakan guru yang meliputi perencanaan, pelaksanaan dan penilaian belum sesuai dengan semestinya. Oleh sebab itu perlunya upaya untuk dapat meningkatkan porses pembelajaran guru tersebut.

Upaya yang dapat dilakukan adalah dengan melaksanakan kegiatan supervisi akademik yang bertujuan untuk meningkatkan 
proses pembelajaran guru. Pada kegiatan ini guru akan dibina untuk melaksanakan proses pembelajaran problem center learning. Model pembelajaran problem centered learning adalah pembelajaran yang berpusat kepada permasalahan (Apriliana, 2019). Pada model problem centered learning ini siswa disajikan permasalahan untuk dipecahkan sehingga siswa aktif menemukan informasi (Cook et al, 2017). Selain keaktifan siswa ini dapat dijadikan sarana untuk melakukan penilaian keterampilan dan sikap.

Penelitian ini didukung oleh penelitian yang dilakukan oleh Karnati (2019) yang menyatakan bahwa supervisi akademik yang dilakukan kepala sekolah mampu meningkatkan kompetens guru dalam mengembangkan RPP. Namun penelitian ini menjadi berbeda yaitu supervisi akademik yang dilakukan difokuskan kepada peningkatkan kemampuan guru sekolah dasar dalam mengembangkan RPP, melaksanakan pembelajaran dengan model problem center learning dan mengembangkan penilaian hasil belajar. Oleh sebab itu tujuan penelitian ini adalah untuk mengetahui peningkatkan keterampilan guru dalam melaksanakan proses pembelajaran menggunakan model problem centered learning melalui kegiatan supervisi akademik.

\section{METODE PENELITIAN}

Penelitian ini merupakan penelitian tindakan sekolah dengan menyadur proses pelaksanaan penelitian tindakan kelas Mc Taggart dan Kemmist. Penelitian ini terdiri dari tahap perencanaan, pelaksanaan, pengamatan dan refleksi. Pada tahapan perencanaan peneliti menyusun jadwal, penyusun rencana kegiatan dan penyusun instrument penilaian. Pada tahapan pelaksanaan peneliti melakukan kegiatan inti supervisi akademik. Pada tahapan pengamatan dilakukan proses penilaian kepada guru dan pada tahapan refleksi dilakukan proses analisis untuk memperbaiki kesalahan yang terjadi.

Kegiatan penelitian ini dilaksanakan di SDN 28 Rawang Timur Kota Padang sebanyak 10 guru. Teknik pengumpulan data menggunakan lembar observasi pengukuran hasil proses pembeajaran yang meliputi kemampuan perencanaan, kemampuan pelaksanaan dan kemampuan penilaian. Teknik analisis data terdiri dari data kuantitatif. Data kuantitatif untuk menganalis hasil lembar observasi:

1. Menghitung nilai rata-rata pelaksanaan pembelajaran

Adapun rumus yang digunakan yaitu

$$
\begin{gathered}
P=\frac{\text { Skor yang didapat }}{\text { Skor maksimal }} \times 100 \\
\text { 2. Menghitung ketuntasan klasikal } \\
X=\frac{\text { Jumlah guru yang mendapatkan nilai } \geq 75}{\text { Jumlah semua guru }} \times 100
\end{gathered}
$$

Adapun indikator keberhasilan PTS ini adalah keterampilan guru dalam melasksanakan proses pembelajaran mendapakan skor minimal 75 dengan ketuntasan belajar klasikal $75 \%$.

\section{HASIL DAN PEMBAHASAN}

Kegiatan yang dilakukan pada awal penelitian adalah tahapan perencanaan. Tahapan ini terdiri dari proses penyusunan jadwal kegiatan, penentuan strategi pelaksanaan, dan pengembangan intrumen penilaian. Setelah dilakukan perencanaan kegiatan maka dilakukan kegiatan supervisi akademik.

Kegiatan supervisi akademik dilakukan dengan membina guru mengenai pembuatan RPP. RPP yang dikembangkan adalalh RPP kurikulum 2012. Guru dibina mengenai komponen RPP kurikulum 2013 yang terdiri dari data sekolah, matapelajaran, dan kelas/semester, materi pokok, alokasi waktu, tujuan pembelajaran, KD dan indikator pencapaian kompetensi, materi pembelajaran, metode pembelajaran, media, alat dan sumber belajar, langkah-langkah kegiatan pembelajaran; dan penilaian hasil belajar. Guru dibina secara langsung pembuatan RPP dengan menggunakan model problem center learning. Pengembangan RPP ini bertujuan untuk pedoman guru melaksanakan pembelajaran menggunakan model model problem center learning. Selain itu guru juga dilakukan pembinaan terhadap pembuatan penilaian hasil belajar. Guru dibina untuk dapat mengembangkan penilaian pembelajaran yang meliputi aspek keterampilan, pengetahuan dan sikap.

Setelah guru dibina mengembangkan RPP dan system penilaian hasil belajar, maka selanjutnya guru diminta untuk 
mengimplementasikanya dalam proses pembelajaran dikelas. Guru melaksanakan proses pembelajaran model problem center learning yang telah dirancang. Sembari guru melaksanakan proses pembelajaran, dilakukan juga pengamatan dan penilaian terhadap proses pembelajaran yang dilaksanakan oleh guru menggunakan problem learning center. Selain itu RPP dan penilaian hasil belajar juga dilakukan penilaian. Adapun rekapitulasi penilaian tersebut dapat dilihat pada tabel berikut:

Tabel 1. Rekapitulasi Penilaian Siklus 1

\begin{tabular}{lc}
\hline \multicolumn{1}{c}{ Aspek } & Skor Rata-Rata \\
\hline Perancangan RPP & 67.19 \\
Perancangan penilaian & 70.17 \\
Pelaksanaan Pembalajaran & 65.16 \\
\hline
\end{tabular}

Dari tabel 1 tersebut dapat dilihat bahwa guru mendapatkan skor rata-rata 64,92. Hasil pengamatan tersebut kemudian dianalisi pada tahapan refleksi.

Pada tahapan refleksi dilakukan analisis terhadap temuan yang dilakukan selama proses pelaksanaan. Berdasarkan temuan didapatkan skor 64.92. Hal ini membuktikan bahwa belum tercapainya indicator keberhasilan yang ditetapkan. Selain itu pada berdasarkan lembar pengamatan juga ditemukan beberapa kegiatan yang belum maksimal yaitu guru belum mampu merancang media pembelajaran yang tepat dengan materi yang diajarkan, langkah-langkah problem learning center belum maksimal dijalankan oleh guru dan guru masih focus kepada pelaksanakaan penilaian kognitif saja. Dari hal tersebut maka peneliti dan guru sepakat untuk melanjutkan perbaikan pada siklus kedua.

Kegiatan pada siklus kedua dilakukan dengan tahapan perencanaan yang terdiri dari kegiatan proses penyusunan jadwal kegiatan, penentuan strategi pelaksanaan, dan pengembangan intrumen penilaian. Setelah dilakukan perencanaan kegiatan maka dilakukan kegiatan supervisi akademik.

Kegiatan pada tahapan pelaksanaan dilakukan dengan membina Kembali guru untuk mengembangkan RPP dan system penilaian. Guru dibina untuk memperhatikan komponen RPP dan menyesuaikan dengan proses pembelajaran problem center learning. Selain itu guru Kembali dibina dalam pengembangan penilaian dan memastikan bahwa penilaian yang dikembangkan harus meliputi aspek keterampilan, pengetahuan dan sikap.

Selanjutnya, guru menerapkan RPP dan system penilaian yang telah dirancang pada prose pembelajaran dikelas. Pada proses pembelajaran yang dilaksanakan oleh guru menggunakan model problem center learning, dilakukan juga pengamatan dan penilaian terhadap proses pembelajaran yang dilaksanakan oleh guru menggunakan problem learning center. Selain itu RPP dan penilaian hasil belajar juga dilakukan penilaian. Adapun rekapitulasi penilaian tersebut dapat dilihat pada tabel berikut:

Tabel 2. Rekapitulasi Penilaian Siklus 2

\begin{tabular}{lc}
\hline \multicolumn{1}{c}{ Aspek } & Skor Rata-Rata \\
\hline Perancangan RPP & 81.25 \\
Perancangan penilaian & 83.19 \\
Pelaksanaan Pembalajaran & 86.12 \\
Rata-rata & 83.81 \\
\hline \multicolumn{1}{c}{ Rata-rata } & 83.81
\end{tabular}


Dari tabel 2 tersebut dapat dilihat bahwa guru mendapatkan skor rata-rata 83.81. Hasil pengamatan tersebut kemudian dianalisi pada tahapan refleksi.

Pada tahapan refleksi dilakukan analisis terhadap temuan yang dilakukan selama proses pelaksanaan. Berdasarkan temuan didapatkan skor 83.81. Hal ini membuktikan bahwa telah tercapainya indicator keberhasilan yang ditetapkan. Selain itu pada berdasarkan lembar pengamatan juga ditemukan bahwa guru telah melaksanakan semua kegiatan dengan benar. Maka berdasarkan kesepakatan dinyatakan bahwa penelitian dicukupkan pada siklus kedua.

Penelitian ini membuktikan bahwa dengan menggunakan supervisi akademik dapat meningkatkan keterampilan mengajar guru menggunakan model problem center learning. Penelitian ini didukung oleh penelitian yang dilakukan oleh Azwardi (2020) yang menyatakan bahwa supervisi akademik dapat meningkatkan kompetensi guru dalam mengembangkan bahan ajar. Penelitian ini memiliki kesamaan yaitu menggunakan kegiatan supervisi akademik untuk meningkatkan kompetensi guru. Namun menjadikan temuan yang berbeda adalah pada penelitian tesebut dalam upaya meningkatkan kompetensi guru dalam mengembangkan bahan ajar sedangkan pada penelitian ini ditemukan fakta bahwa supervisi akademik dapat meningkatkan keterampilan mengajar guru dengan menggunakan model problem center learning yang meliputi perencanaan pembelajaran, pelaksanaan pembelajaran dan penilaian hasil belajar.

Supervisi akademik merupakan kegiatan yang dilakukan oleh kepala sekolah/pengawas kepada guru dalam rangka meningkatkan kualitas guru dalam proses pembelajaran di sekolah (Azwardi, 2019). Pada penelitian ini supervisi akademik dapat meningkatkan keterampilan mengajar guru dengan menggunakan model problem center learning yang meliputi perencanaan pembelajaran, pelaksanaan pembelajaran dan penilaian hasil belajar hal ini dikarenakan oleh beberapa factor. Pada kegiatan supervisi akadmeik, kepala sekolah dapat secara langsung melakukan pembinaan kepada guru dalam mendesain dan menyusun RPP dan penilaian yang sebagaimana mestinya. Kepala sekolah dapat melakukan pembinaan secara klasikal maupun personal agar guru dapat Menyusun proses pembelajaran. Hal ini selaras dengan pendapat yang menyatakan bahwa supervisi akademik dapat meningkatkan kemampuan guru dalam merancangan proses pembelajaran (Agustina and Kristiawan, 2020; Saihu, 2020; Martono and Prihatin, 2021). Selain itu guru juga dapat membina dan melatih guru agar dapat melaksankaan proses pembelajaran yang sesuai dengan karakteristik siswa sekolah dasar secara langsung. Kepala sekolah mampu mengarahkan model pembelajaran yang inovatif yang dapat dilakukan oleh guru. Hal ini selaras dengan pendapat yang menyatakan bahwa dengan kegiatan supervisi akademik dapat meningkatkan kemampuan guru dalam melaksanakan proses pembelajaran (Prasetyono et al, 2018; Ahmad et al, 2020).

\section{SIMPULAN DAN REKOMENDASI}

Berdasarkan penelitian yang dilakukan ditemukan guru mendapatkan skor rata-rata keterampilan pada siklus 1 sebesar 88,86 dan mendapatkan skor rata-rata pada siklus 2 sebesar 83,59 . Hal ini menyimpulkan bahwa terjadinya peningkatan keterampilan proses pembelajaran guru melalui kegiatan akademik. Penelitian ini menyarankan agar perlu kesepakatan jadwal dengan guru agar pelaksanaan supervisi dapat terlaksana dengan optimal. Penelitian ini merekomendasikan agar kepala sekolah dapat melaksanakan kegiatan supervise secara berkelanjutan agar dapat meningkatkan kualitas pembelajaran guru.

\section{DAFTAR PUSTAKA}

Adewale, O. S. (2014). Instructional Improvement of Secondary School Teachers through Effective Academic Supervision by the Vice-Principals. Journal of Education and Human Development, 3(2), 607-617.

Agustina, E., \& Kristiawan, M. (2020). Developing a Module of Academic Supervision for Headmaster of Madrasah Ibtidaiyah. Education Journal, 3(1), 2636. 
Ahmad, A., \& Saefurrohman, S. (2020). Teacher' s Perception of Academic Supervision of the School Headmaster. Utopía y Praxis Latinoamericana, 25(6), 289-302.

Apriliana, L. P., Handayani, I., \& Awalludin, S. A. (2019). The Effect of a Problem Centered Learning on Students' Mathematical Critical Thinking. Journal of Research and Advances in Mathematics Education, 4(2), 124-133.

Ariani, Y., \& Kenedi, A. K. (2018). Model Polya dalam peningkatan hasil belajar matematika pada pembelajaran soal cerita volume di sekolah dasar. Jurnal Inspirasi Pendidikan, 8(2), 25-36.

Astimar, N., Helsa, Y., \& Kenedi, A. K. (2019, December). The review of utilization in natural environment by the teacher as a source for learning science at elementary school in low class. In Journal of Physics: Conference Series (Vol. 1424, No. 1, p. 012036). IOP Publishing.

Azwardi, A. (2019). Academic supervision and work motivation as a contributing factor of teacher competence. Indonesian Educational Administration and Leadership Journal, 1(1), 71-82.

Azwardi, A. (2020). Efforts to improve teacher competency in developing learning materials through collaborative academic supervision. Indonesian Educational Administration and Leadership Journal, 2(1), 1-12.

Budiarti, E. M., Gunawan, I., \& Pambudi, B. A. (2020, December). The Effect of Spiritual Leadership and Academic Supervision on Teacher Performance. In 6th International Conference on Education and Technology (ICET 2020) (pp. 157-161). Atlantis Press.

Cook, K. E., Han, Y. L., Shuman, T. R., \& Mason, G. (2017). Effects of integrating authentic engineering problem centered learning on student problem solving. International Journal of Engineering Education, 33(1), 272-282.

Eliyasni, R., Kenedi, A. K., \& Sayer, I. M. (2019). Blended Learning and Project Based
Learning: The Method to Improve Students' Higher Order Thinking Skill (HOTS). Jurnal Iqra': Kajian Ilmu Pendidikan, 4(2), 231-248.

Hendri, S., \& Kenedi, A. K. (2018). Pengembangan perangkat pembelajaran matematika berbasis discovery learning untuk meningkatkan kemampuan pemecahan masalah siswa kelas VIII SMP. Jurnal Inspirasi Pendidikan, 8(2), 10-24.

Karnati, N. (2019). Academic Supervision To Improve The Competence Of Elementary School Teachers. Australasian Journal of Educational Technology, 35(1), 3646.

Kenedi, A. K., Chandra, R., \& Fitria, Y. (2019, December). Problem based learning: a way to improve critical thinking ability of elementary school students on science learning. In Journal of Physics: Conference Series (Vol. 1424, No. 1, p. 012037). IOP Publishing.

Kenedi, A. K., Eliyasni, R., \& Fransyaigu, R. (2019, December). Jigsaw using animation media for elementary school. In Journal of Physics: Conference Series (Vol. 1424, No. 1, p. 012027). IOP Publishing.

Kenedi, A. K., Helsa, Y., \& Hendri, S. (2018). Pengembangan Bahan Ajar Matematika Berbasis Alquran Di Sekolah Dasar. Jurnal Inovasi Pendidikan Dan Pembelajaran Sekolah Dasar, 2(1).

Kenedi, A. K., Helsa, Y., Ariani, Y., Zainil, M., \& Hendri, S. (2019). Mathematical Connection of Elementary School Students to Solve Mathematical Problems. Journal on Mathematics Education, 10(1), 69-80.

Kenedi, A. K., Hendri, S., \& Ladiva, H. B. (2018). Kemampuan Koneksi Matematis Siswa Sekolah Dasar Dalam Memecahkan Masalah Matematika. Numeracy, 5(2), 226-235.

Kuncoro, T., \& Dardiri, A. (2017, September). Teacher performance and work environment in the instructional process 
in vocational school. In AIP Conference Proceedings (Vol. 1887, No. 1, p. 020043). AIP Publishing LLC.

Martono, S., \& Prihatin, T. (2021). The Effect of Academic Supervision and Principal Leadership Through Performance Motivation Toward The Teacher Performance. Educational Management, 210-220.

Pambudi, B. A., \& Gunawan, I. (2020, December). The Effect of Learning Leadership and Academic Supervision on Teacher Teaching Skills in the Covid-19 Pandemic. In 6th International Conference on Education and Technology (ICET 2020) (pp. 1-5). Atlantis Press.

Prasetyono, H., Abdillah, A., \& Fitria, D. (2018). Academic supervision toward teacher's performance through motivation as intervening variable. Journal of Education and Learning (EduLearn), 12(2), 188-197.

Rahabav, P. (2016). The Effectiveness of Academic Supervision for Teachers. Journal of Education and Practice, 7(9), 47-55.

Rasmita, D. (2019). Upaya Meningkatan Kompetensi Guru dalam Pelaksanaan Proses Pembelajaran Melalui Supervisi Akademik di SD Negeri 017 Pasir Emas. Jurnal PAJAR (Pendidikan dan Pengajaran), 3(3), 560-569.

Saihu, S. (2020). The Urgency Of Total Quality Management In Academic Supervision To Improve The Competency of Teachers. Edukasi Islami: Jurnal Pendidikan Islam, 9(02), 297-323. 